\title{
Free vibration analysis of laminated composite beam under room and high temperatures
}

\author{
Yusuf Cunedioglu $^{* 1}$ and Bertan Beylergil ${ }^{2 a}$ \\ ${ }^{1}$ Department of Mechanical Engineering, Faculty of Engineering, Nigde University, 51245 Nigde, Turkey \\ ${ }^{2}$ Department of Mechanical Engineering, Faculty of Engineering, Izmir Institute of Technology, \\ Gulbahce Campus, 35437 Urla, Izmir, Turkey
}

(Received June 7, 2012, Revised May 2, 2014, Accepted May 9, 2014)

\begin{abstract}
The aim of this study is to investigate the effects of the beam aspect ratio $(\mathrm{L} / \mathrm{h})$, hole diameter, hole location and stacking layer sequence $\left([0 / 45 /-45 / 90]_{\mathrm{s}},[45 / 0 /-45 / 90]_{\mathrm{s}}\right.$ and $\left.[90 / 45 /-45 / 0]_{\mathrm{s}}\right)$ on natural frequencies of glass/epoxy perforated beams under room and high $\left(40,60,80\right.$, and $\left.100^{\circ} \mathrm{C}\right)$ temperatures for the common clamped-free boundary conditions (cantilever beam). The first three out of plane bending free vibration of symmetric laminated beams is studied by Timoshenko's first order shear deformation theory. For the numerical analyses, ANSYS 13.0 software package is utilized. The results show that the hole diameter, stacking layer sequence and hole location have important effect especially on the second and third mode natural frequency values for the short beams and the high temperatures affects the natural frequency values significantly. The results are presented in tabular and graphical form.
\end{abstract}

Keywords: layered structures; cut-out; natural frequencies; finite element analysis

\section{Introduction}

The application of fiber composites has shown a tremendous growth in many fields ranging from trivial, industrial products such as boxes and covers produced in enormous numbers each day, to pipelines and crucial, load bearing parts of large structures. Composites are also extensively used in the aerospace and marine industries. Some important reasons for this popularity are: their high strength (and stiffness) to weight ratio; light weight and resistance to corrosion and chemicals. Cutouts are inescapable in composite structures principally for practical considerations. However, the vibrations may cause sudden failures in consequence of resonance in the presence of cutouts. It is therefore very important to predict the natural frequencies of these structural members precisely. There are many publications in the literature about laminated plate vibration.

Abramovich (1992) studied symmetrically laminated composite beam with different boundary conditions on the basis of Timoshenko-type equations. In the analysis, the shear deformation and the rotary inertia were considered, but with the term representing the joint action of these factors

*Corresponding author, Associate Professor, E-mail: ycunedioglu@nigde.edu.tr

${ }^{a} \mathrm{Ph} . D$. Student, E-mail: bertanbeylergil@iyte.edu.tr 
neglected in the Timoshenko equations. A detailed analytical analysis was carried out to determine the natural frequencies of laminated beams. Abramovich et al. (1995) examined the vibrations of general layered beams by using a novel, precise element method. A dynamic stiffness matrix was calculated; thereafter the problem was solved for any set of boundary conditions, comprising elastic connections and different member assemblies. The natural frequencies at which the dynamic stiffness matrix turned into singular were obtained.

Teh and Huang (1979) investigated a general orthotropic cantilever beam by using two finiteelement models, containing both the shear deformation and the rotary inertia effects. In the analysis, the first-order shear deformation theory was utilized. Chandrashekhara and Bangera (1992) presented a refined shear-flexible beam element, including a higher-order shear deformation theory in the formulation of constitutive equations for the beams. The Poisson effect was also taken into account which is frequently ignored in a one-dimensional analysis of laminated beams. They reported the frequencies and the corresponding modal shapes for symmetrically laminated orthotropic composite beams. Lee et al. (1992) used the finite-element method for the stress and vibration analysis of composite beams, on the basis of multilayered beam theory. In the finite-element formulation, the principle of maximum potential energy, the continuity of the interlaminar shear stress was considered.

Hodges et al. (1991) presented a simple analytical and a detailed cross-sectional finite element method for analyzing the free vibrations of composite beams. By using these methods, the natural frequencies and the corresponding modal shapes were acquired. Maiti and Sinha (1994) performed bending and free vibration analyses of shear-deformable laminated composite beams by application of the finite-element method. The analysis was based on a higher-order sheardeformation theory and the conventional first-order theory to develop a finite-element model with a nine-node isoparametric element. They investigated the effects of various factors, such as fiber orientation, span/depth ratio, and boundary conditions, on the non-dimensionalized fundamental frequencies, non-dimensionalized deflections, and stresses. They showed that the differences between the frequencies and deflections given by the first-order and higher-order sheardeformation theories were inconsequential in the matter of laminated composite beams. Shi and Lam (1999) acquired the same result for the fundamental frequency by using a third-order beam theory.

Khdeir (1994) investigated the free-vibration behavior of cross-ply rectangular beams, with arbitrary boundary conditions. The author reported that the difference between different sheardeformation theories was negligible. Teboub and Hajela (1995) integrated the equations of motion for the free vibration of general layered composite beams on the basis of the first-order sheardeformation theory. They investigated the effect of Poisson ratio, layer width and stacking, and boundary conditions on the natural frequencies.

Krishnaswamy et al. (1992) presented analytical solutions to the vibrations problem for general layered clamped-clamped and clamped-supported composite beams. They used Hamilton's principle for the purpose of developing the dynamic equations of free-vibrations. The energy formulation they used held both the shear deformation and the rotary inertia.

Bezazi et al. (2001, 2003a, b) investigated the effect of the stacking layer sequence over the damage tolerance and fatigue the cross-ply laminates by utilizing a three-dimensional finite element analysis. Davidson et al. (1995) reported that the stacking sequence affects the loss rate of energy. Sun and Jen (1987) and El Mahi et al. (1995) studied the influence of the stacking layer sequence in the event of laminates $\left(0_{\mathrm{m}} / 90_{\mathrm{n}}\right)_{\mathrm{s}}$ and $\left(90_{\mathrm{n}} / 0_{\mathrm{n}}\right)_{\mathrm{s}}$. They examined the loss of rigidity and energy in cross laminates during fatigue tests for tensile loading. 
Rajamani and Prabhakaran (1977) examined the influence of a hole on the natural vibration characteristics of isotropic and orthotropic plates with simply-supported and clamped boundary conditions. Sakiyama et al. (2003) investigated the natural vibration characteristics of an orthotropic plate with a square hole via the Green function supposing that the hole as an extremely thin plate. Lee (1984) performed vibration experiments on the rectangular plates with a hole in air and water. Kim et al. (1990) tested the lateral vibrations of rectangular plates by using simple polynomials in the Rayleigh-Ritz method. Paramasivam (1973) utilized the finite difference method for a simply-supported and clamped rectangular plate with a rectangular hole. Aksu and Ali (1976) analyzed a rectangular plate with more than two holes by using the finite difference method. Ram and Sinha (1992) investigated the effects of moisture and temperature on the free vibration of laminated composite plates. Numerical results revealed that the increase of moisture concentration and temperature causes reduction in natural frequencies of symmetric and antisymmetric laminates with simply supported and clamped boundary conditions. Sharma and Mittal (2010) published a review on stress and vibration analysis of composite plates. Alam et al. (2012) presented an efficient one dimensional finite element model has been presented for the dynamic analysis of composite laminated beams, using the efficient layer-wise zigzag theory. Kim and Choi (2013) derived a super convergent laminated composite beam element for the lateral stability analysis.

In this study, the effects of the beam aspect ratio $(L / h)$, hole diameter, hole location and stacking layer sequence $\left([0 / 45 /-45 / 90]_{\mathrm{s}},[45 / 0 /-45 / 90]_{\mathrm{s}}\right.$ and $\left.[90 / 45 /-45 / 0]_{\mathrm{s}}\right)$ on natural frequencies are investigated under room and high $\left(40,60,80\right.$, and $\left.100^{\circ} \mathrm{C}\right)$ temperatures. The first three of out of plane bending free vibration modes are studied. For the numerical analyses, ANSYS 13.0 software package is used. The numerical results show that the hole diameter, stacking layer sequence and hole location have significant effect on the second and third mode natural frequency values especially for the short beams. It is worthy to note that temperature affects the natural frequency values. The results are presented in tabular and graphical form.

\section{Timoshenko theory}

The Timoshenko beam theory includes the effect of transverse shear deformation. As a result, a plane normal to the beam axis before deformation does not remain to the beam axis any longer after deformation. The energy method is used to derive the finite element matrix equation (Kwon and Bang 2000).

Let $u$ and $v$ be the axial and transverse displacements of a beam, respectively. Due to the transverse shear deformation, the slope of beam $\theta$ is different from $d v / d x$. Instead, the slope equals $(\mathrm{d} v / \mathrm{d} x)-\gamma$ where $\gamma$ is the transverse shear strain. As a result, the displacement field in the Timoshenko beam can be written as

$$
\begin{gathered}
u(x, y)=-y \theta(x) \\
v(x)=v
\end{gathered}
$$

where the $z$-axis is located along the neutral axis of the beam and the beam is not subjected to an axial load such that the neutral axis does not have the axial strain. From Eq. (1) and Eq. (2) the axial and shear strains are 


$$
\begin{gathered}
\varepsilon=-y \frac{d \theta}{d x} \\
\gamma=-\theta+\frac{d v}{d x}
\end{gathered}
$$

The strain energy for an element of length $l$ is

$$
U=\frac{b}{2} \int_{0}^{l} \int_{-h / 2}^{h / 2} \varepsilon^{T} E \varepsilon d y d x+\frac{b \mu}{2} \int_{0}^{l} \int_{-h / 2}^{h / 2} \gamma^{T} G_{\gamma} d y d x
$$

where the first term is the bending strain energy and the second term is the shear strain energy. Besides, $b$ and $h$ are the width and height of the beams respectively, and $\mu$ is the correction factor for shear energy.

First, substituting Eqs. (3)-(4) into Eq. (5) and taking integration with respect to $y$ gives

$$
U=\frac{1}{2} \int_{0}^{l}\left(\frac{d \theta}{d x}\right)^{T} E I\left(\frac{d \theta}{d x}\right) d x+\frac{\mu}{2} \int_{0}^{l}\left(-\theta+\frac{d v}{d x}\right)^{T} G A\left(-\theta+\frac{d v}{d x}\right) d x
$$

where $I$ and $A$ are the moment of inertia and area of the beam cross-section respectively.

In order to derive the element stiffness matrix for the Timoshenko beam, the variables $v$ and $\theta$ need to be interpolated within each element. As seen in Eq. (6), $v$ and $\theta$ are independent variables. That is, we can interpolate them independently using proper shape functions. We use the simple linear shape functions for both independent variables. That is

$$
\begin{aligned}
& v=\left[H_{1} H_{2}\right]\left\{\begin{array}{l}
v_{1} \\
v_{2}
\end{array}\right\} \\
& \theta=\left[H_{1} H_{2}\right]\left\{\begin{array}{l}
\theta_{1} \\
\theta_{2}
\end{array}\right\}
\end{aligned}
$$

The functions $H_{1}(x)$ and $H_{2}(x)$ are called Hermitian shape functions. Using Eq. (7) and Eq. (8) along with the strain energy expression Eq. (6) yields the following element stiffness matrix for the Timoshenko beam

$$
\left[K^{e}\right]=\left[K_{b}^{e}\right]+\left[K_{s}^{e}\right]
$$

where

$$
\left[K_{b}^{e}\right]=\frac{E I}{l}\left[\begin{array}{cccc}
0 & 0 & 0 & 0 \\
0 & 1 & 0 & -1 \\
0 & 0 & 0 & 0 \\
0 & -1 & 0 & 1
\end{array}\right]
$$




$$
\left[K_{s}^{e}\right]=\frac{\mu G A}{4 l}\left[\begin{array}{cccc}
4 & 2 l & -4 & 2 l \\
2 l & l^{2} & -2 l & l^{2} \\
-4 & -2 l & 4 & -2 l \\
2 l & l^{2} & -2 l & l^{2}
\end{array}\right]
$$

The bending stiffness term, Eq. (10), is obtained using the exact integration of the bending strain energy but the shear stiffness term, Eq. (11), is obtained using the reduced integration technique. Lastly, the diagonalized mass matrix can be written as

$$
\left[M^{e}\right]=\frac{\rho A l}{78}\left[\begin{array}{cccc}
39 & 0 & 0 & 0 \\
0 & l^{2} & 0 & 0 \\
0 & 0 & 39 & 0 \\
0 & 0 & 0 & l^{2}
\end{array}\right]
$$

For free vibration of a beam, the eigenvalue problem is

$$
\left(\left[K^{e}\right]-\omega^{2}\left[M^{e}\right]\right)\{\bar{d}\}=0
$$

where $\omega$ is the angular natural frequency in radians per second and $\{\bar{d}\}$ is the mode shape.

\subsection{Calculation of the beam rigidity}

In Eq. (10), the term of beam rigidity (EI) is as shown (Kwon and Bang 2000)

$$
E I=\frac{b}{D_{11}^{*}}
$$

where $D_{i j}^{*}(i, j=1,2,6)$ denote the elements of the inverse of the bending stiffness matrix $[D]$.

\subsection{Calculation of the shear modulus}

In Eq. (11), the term of shear modulus (GA) is as shown (Kwon and Bang 2000)

$$
G A=\frac{b}{A_{55}^{*}}
$$

where $A_{i j}^{*}(\mathrm{i}, \mathrm{j}=4,5)$ denote the elements of the inverse of extensional stiffness matrix $[A]$.

\section{Numerical verification}

In order to validate the finite element model, an example taken from the literature (Hassan et al. 2009 ) is analyzed and then numerical results are compared with exact solutions. The geometry and 


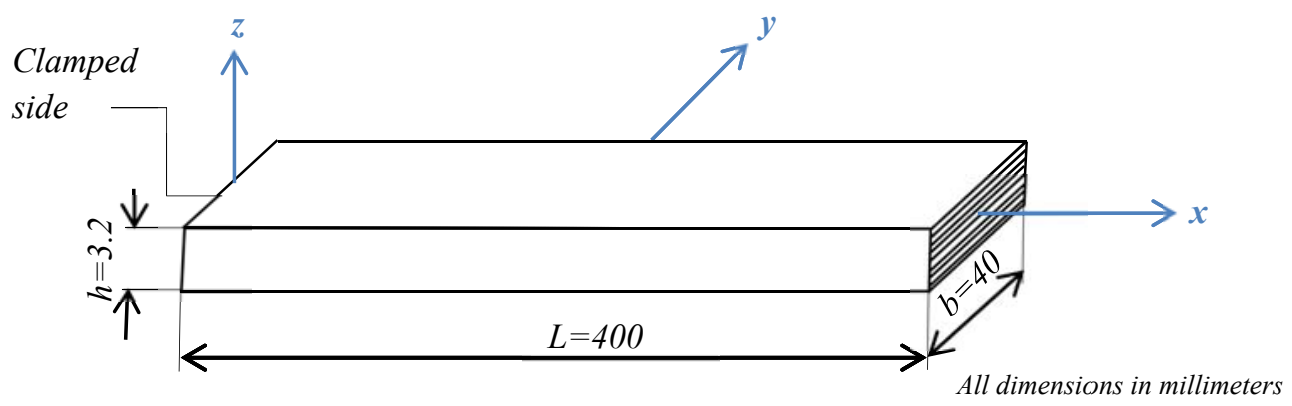

Fig. 1 Mesh grid of topographic model

Table 1 The mechanical properties of the laminated composite beam used for the verification (Hassan et al. 2009)

\begin{tabular}{ccccccc}
\hline \hline $\mathbf{E}_{\mathbf{1}}(\mathrm{GPa})$ & $\mathbf{E}_{\mathbf{2}}=\mathbf{E}_{\mathbf{3}}(\mathrm{GPa})$ & $\mathbf{G}_{\mathbf{1 2}}=\mathbf{G}_{\mathbf{1 3}}(\mathrm{GPa})$ & $\boldsymbol{v}_{\mathbf{1 2}}=\boldsymbol{v}_{\mathbf{1 3}}(-)$ & $\mathbf{G}_{\mathbf{2 3}}(\mathrm{GPa})$ & $\boldsymbol{v}_{\mathbf{2 3}}(-)$ & $\boldsymbol{\rho}\left(\mathrm{kg} / \mathrm{m}^{3}\right)$ \\
\hline 46.2 & 14.70 & 5.35 & 0.31 & 7.54 & 0.41 & 2040
\end{tabular}

1-fibres direction, 2-transverse direction, 3-thickness direction.
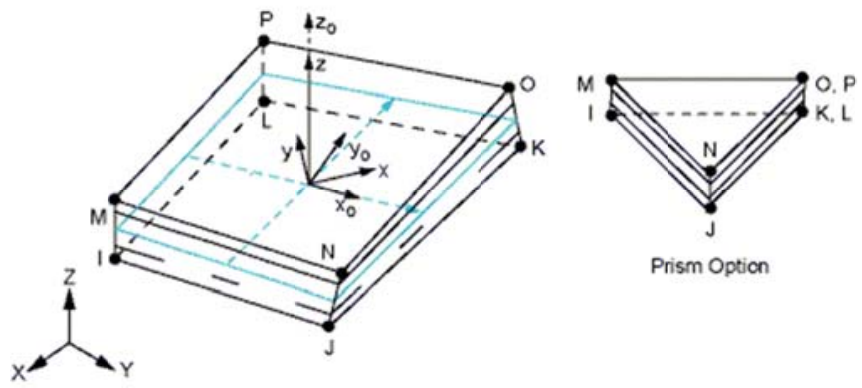

$\mathrm{x}_{0}=$ Element $\mathrm{x}$-axis if ESYS is not supplied. $\mathrm{x}=$ Element $\mathrm{x}$-axis if ESY'S is supplied.

Fig. 2 3D 8 node layered solid-shell element (SOLSH190)

dimensions of the composite beams used for the validation of finite element method is shown in Fig. 1.

The composite beams were $E$ glass fiber/epoxy with the dimensions of $400 \times 40 \times 3.2 \mathrm{~mm}$ (length $x$ width $x$ thickness). They were composed of 8 layers with equal thickness. The lamination scheme of the composite beams was $[(0 / 90)]_{2 s}$. The material properties were given in Table 1 .

Modal analysis is carried out by using. ANSYS 13.0 software package. As the element type, solid-shell (SOLSH190) element with six degree of freedom (translations in the nodal $x, y$, and $z$ directions and rotations about the nodal $x, y$, and $z$-axes) is chosen (see Fig. 2). In total, 8442 nodes and 1000 elements are used for the beam modeling.

Table 2 shows the comparison of out of plane natural frequencies of the composite beam and close agreement was found between the numerical and theoretical results.

The out of plane and bending vibration mode shapes of the composite beam are shown in Fig. 3 . 
Table 2 Comparison of out of plane bending natural frequencies with the theoretical results

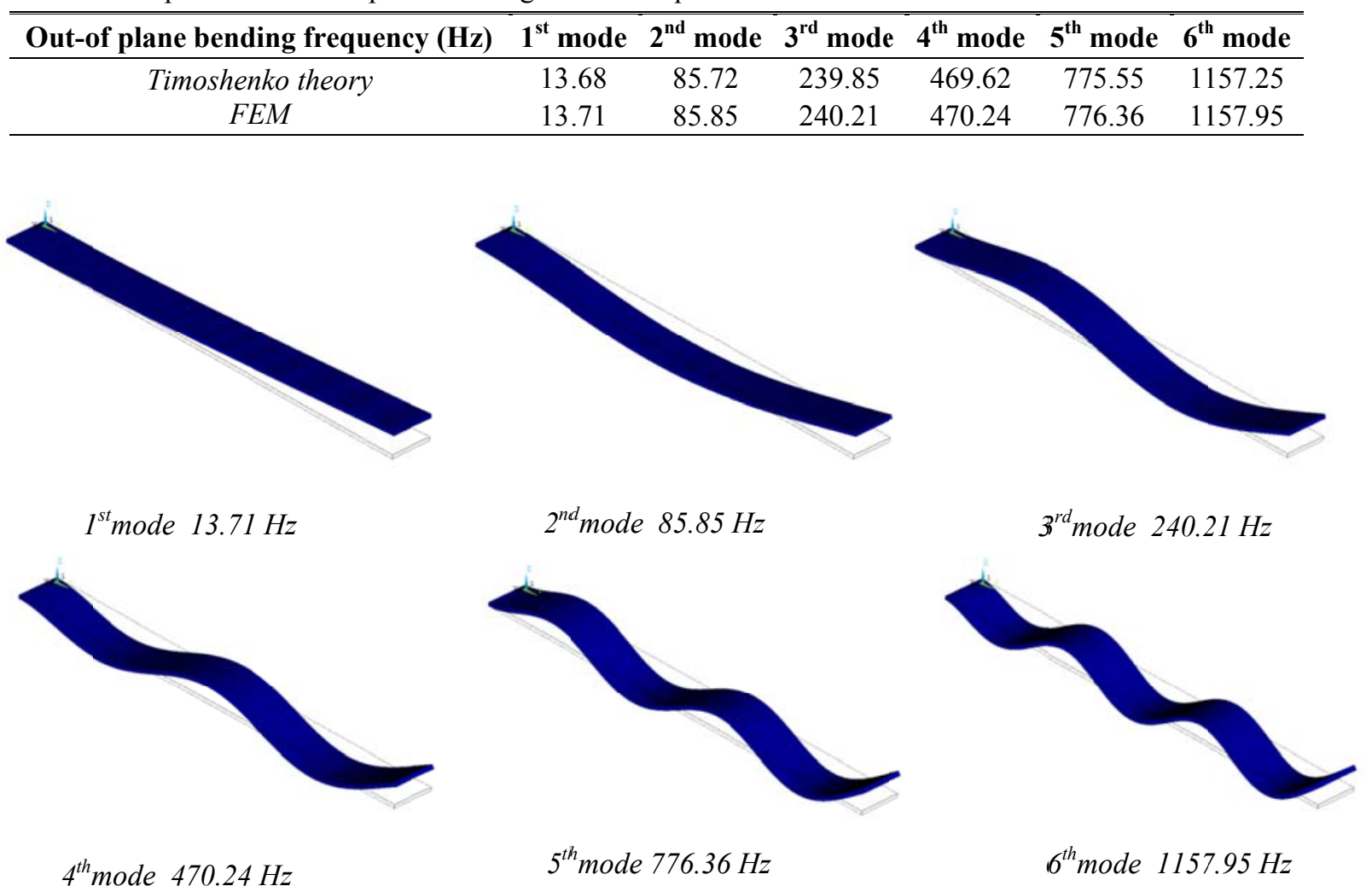

Fig. 3 The first six out of plane bending vibration mode shapes of composite beam
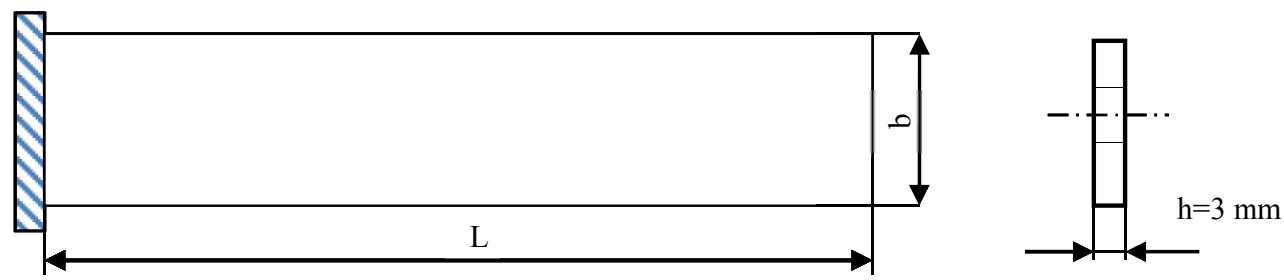

Fig. 4 The laminated composite beam.

\section{Statement of the problem}

The model is considered as a cantilever laminated composite beam with three different span lengths as $L_{1}=0.3 \mathrm{~m}\left(L_{1} / h=100\right) ; L_{2}=0.225 \mathrm{~m}\left(L_{2} / h=75\right)$; and $\left.L_{3}=0.15 \mathrm{~m}\left(L_{3} / h=50\right)\right)$ respectively, solid rectangular cross section (width $\mathrm{b}=0.02 \mathrm{~m}$, thickness $\mathrm{h}=0.003 \mathrm{~m}$ ) and the hole diameters are chosen as $\varnothing d=5,10,15 \mathrm{~mm}$ as shown in Fig. 4. Three different configurations, namely [0/45/-45/90], $[45 / 0 /-45 / 90]_{\mathrm{s}}$ and $[90 / 45 /-45 / 0]_{\mathrm{s}}$ is considered.

The thickness of each layer is identical for all layers in the laminates. $G_{23}$ and $v_{23}$ are calculated by using the following formulas (Kisa 2004) 


$$
\begin{gathered}
\rho=\rho_{f} V+\rho_{m}(1-V) \\
E_{11}=E_{f} V+E_{m}(1-V) \\
E_{22}=E_{m}\left[\frac{E_{f}+E_{m}+\left(E_{f}-E_{m}\right) V}{E_{f}+E_{m}-\left(E_{f}-E_{m}\right) V}\right] \\
v_{12}=v_{f} V+v_{m}(1-V) \\
v_{23}=v_{f} V+v_{m}(1-V)\left[\frac{1+v_{m}-v_{12} E_{m} / E_{11}}{1-v_{m}{ }^{2}+v_{m} v_{12} E_{m} / E_{11}}\right] \\
G_{23}=\frac{E_{22}}{2\left(1+v_{23}\right)}
\end{gathered}
$$

where indices $m$ and $f$ denote matrix and fiber, respectively. $E, G$ and $v$ are the modulus of elasticity, the modulus of rigidity, the Poisson's ratio respectively. The value of fiber poisson's ratio $\left(v_{f}\right)$ is taken as 0.23 . Material properties of the beams investigated are assumed to be same in all layers as given in Table 3 .

We investigate the effects of beam span length-height ratio $(L / h)$, hole diameter $(\varnothing d)$, hole location $(a / L)$ and different temperatures on the free vibration behavior of the laminated composite cantilever beams. As in the verification, solid-shell (SOLSH190) element with six degree of freedom (translations in the nodal $x, y$, and $z$ directions and rotations about the nodal $x, y$, and $z$ axes) was used. The laminated composite beam is oriented at $[90 / 45 /-45 / 0]_{\mathrm{s}}$ as seen in Fig. 5(a). Mesh arrangement around the circular hole is shown in Fig. 5(b).

\section{Results and discussion}

The effect of $a / L$ ratios and hole diameter on the natural frequencies for $L / h=100$ and stacking sequence $[0 / 45 /-45 / 90]_{\mathrm{s}}$ is demonstrated in Fig. 6. As shown in Fig. 6(a), the minimum first mode

Table 3 The mechanical properties of the laminated composite beams (Aktas and Karakuzu 2009)

\begin{tabular}{ccccccccc}
\hline \hline $\begin{array}{c}\text { Temperature } \\
\left({ }^{\circ} \mathbf{C}\right)\end{array}$ & $\begin{array}{c}\mathbf{E}_{\mathbf{1}} \\
(\mathbf{M P a})\end{array}$ & $\begin{array}{c}\mathbf{E}_{\mathbf{2}}=\mathbf{E}_{\mathbf{3}} \\
(\mathbf{M P a})\end{array}$ & $\begin{array}{c}\mathbf{G}_{\mathbf{1 2}}=\mathbf{G}_{\mathbf{1 3}} \\
(\mathbf{M P a})\end{array}$ & $\begin{array}{c}\mathbf{G}_{\mathbf{2 3}} \\
(\mathbf{M P a})\end{array}$ & $\mathbf{v}_{\mathbf{1 2}}=\mathbf{v}_{\mathbf{1 3}}$ & $\mathbf{v}_{\mathbf{2 3}}$ & $\begin{array}{c}\boldsymbol{\rho} \\
\left(\mathbf{k g} / \mathbf{m}^{\mathbf{3}}\right)\end{array}$ & $\begin{array}{c}\text { Ply thickness } \\
(\mathbf{m m})\end{array}$ \\
\hline 20 & 40510 & 13960 & 3105 & 5630 & 0.22 & 0.24 & 1830 & 0.375 \\
40 & 39820 & 11540 & 2629 & 4650 & 0.22 & 0.24 & & \\
60 & 39720 & 11090 & 2561 & 4550 & 0.21 & 0.22 & & \\
80 & 28270 & 6110 & 2053 & 2500 & 0.21 & 0.22 & & \\
100 & 19450 & 5700 & 813 & 2350 & 0.20 & 0.21 & & \\
\hline
\end{tabular}



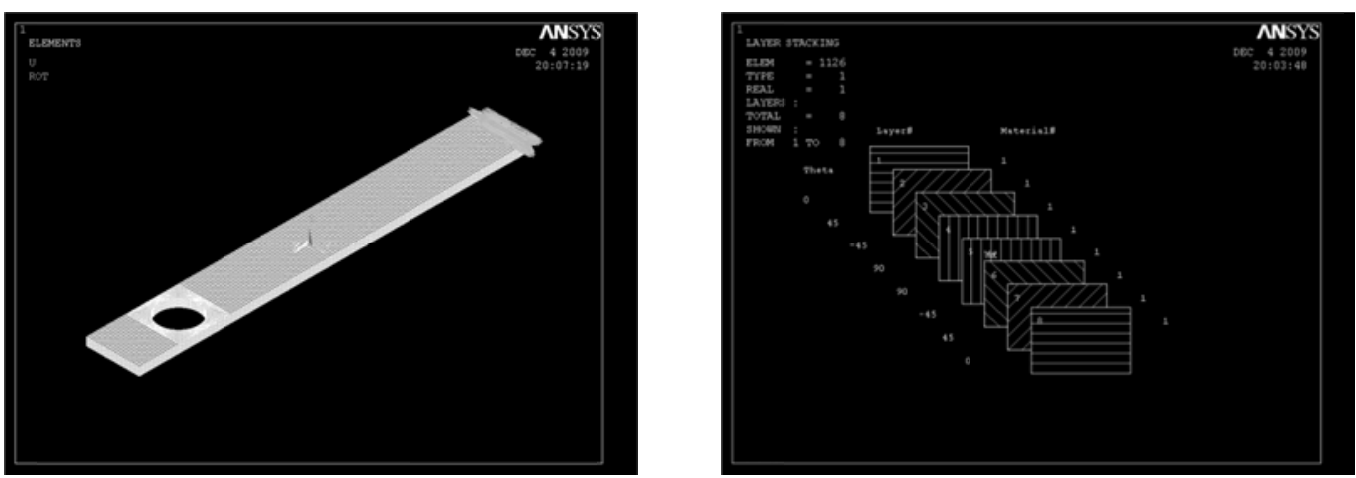

(a)

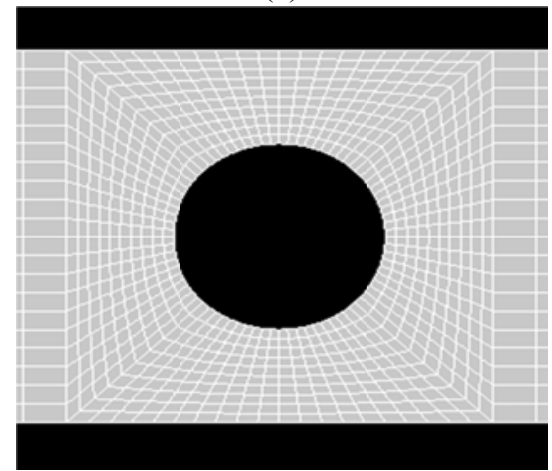

(b)

Fig. 5 (a) The cantilever laminated composite beam with $[0 / 45 /-45 / 90]_{\mathrm{s}}$ fiber orientation (b) Mesh structure around the hole

natural frequency is observed when the location of the circular hole is the nearest to the clamped edge of the beam for the biggest hole diameter. When the biggest hole approaches to the free end of the beam, the first mode values increase linearly. The maximum first mode natural frequency is noticed when the location of the circular hole is the nearest to the clamped edge of the beam for the smallest diameter. Fig. 6(a) also shows decrease in the first mode natural frequency values when the smallest hole approaches to the right free end of the beam. Moreover, when the hole diameter is $10 \mathrm{~mm}$, from the hole location $a / L=2 / 6$ to the right free end of the beam, the first mode values increase gradually. As shown in Fig. 6(b), the maximum second mode natural frequency is observed when the location of the circular hole is the nearest to the clamped edge of the beam for the smallest diameter. In addition to this, the second mode natural frequencies decrease from the clamped edge to the free end for the same hole diameter. The same tendency is observed until the hole approaches to the free end of the beam $(a / L=4 / 6)$ for the other hole diameters. After that, the values begin to increase gradually. The minimum second mode frequency is observed when the hole location is closer to the right free end of the beam $(a / L=4 / 6)$ for the biggest hole diameter. As shown in Fig. 6(c), the maximum third mode natural frequency is observed when the location of the circular hole is the nearest to the clamped edge of the beam for the biggest diameter. And the minimum third mode natural frequency is observed when the location of the circular hole is the nearest to the right free end of the beam for the biggest diameter. The third mode natural frequencies decrease from the clamped edge to the right free end for the other hole diameter. 


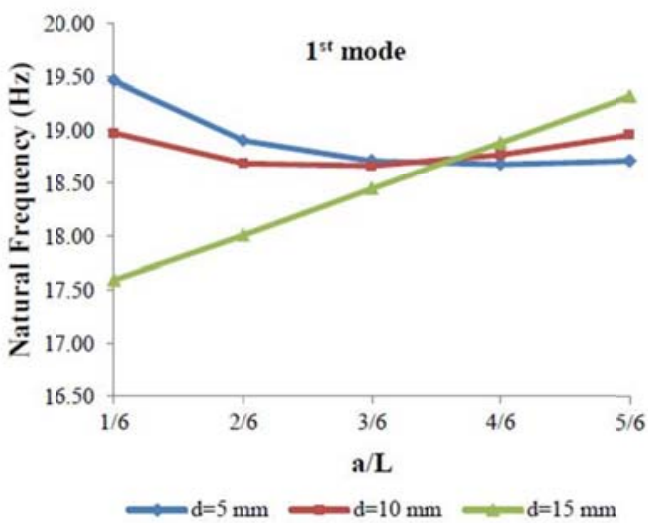

(a)

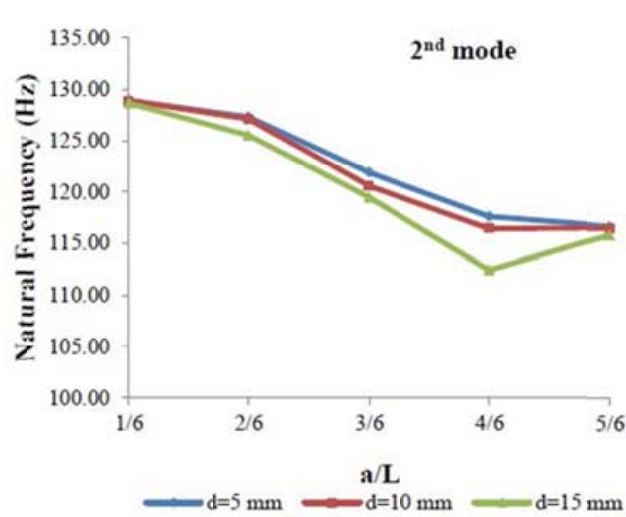

(b)

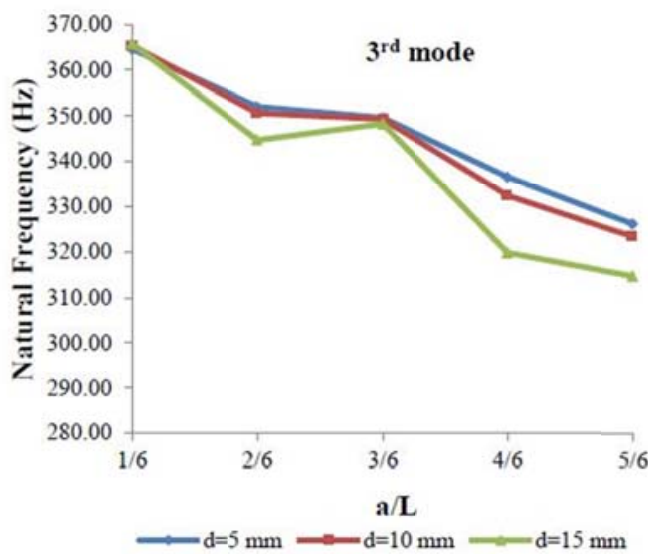

(c)

Fig. 6 The effect of $a / L$ ratios and hole diameter on the natural frequencies $(L / h=100$, Stacking sequence: $[0 / 45 /-45 / 90]_{\mathrm{s}}$, Temperature: $20^{\circ} \mathrm{C}$ )

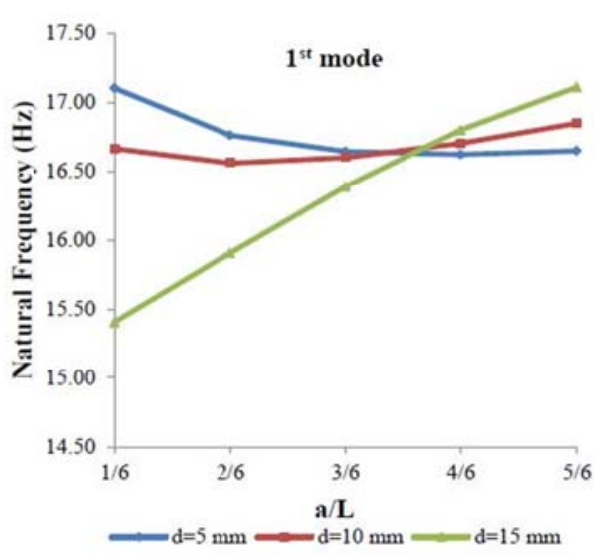

(a)

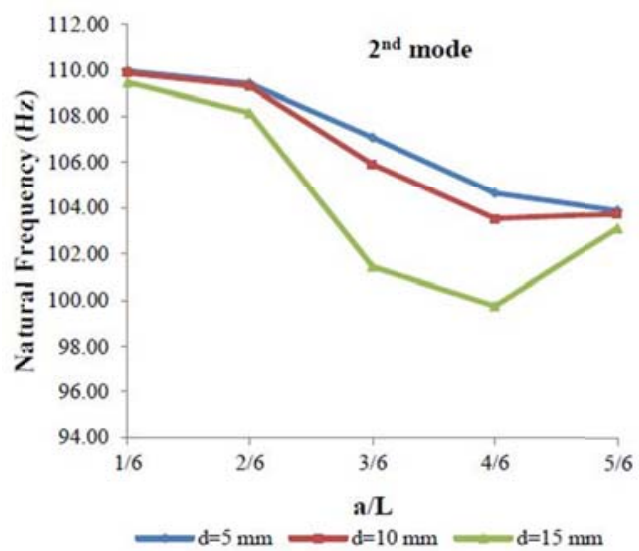

(b)

Fig. 7 The effect of $a / L$ ratiosand hole diameter on the natural frequencies $(L / h=100$, Stacking sequence: $[45 / 0 /-45 / 90]_{\mathrm{s}}$, Temperature: $20^{\circ} \mathrm{C}$ ) 


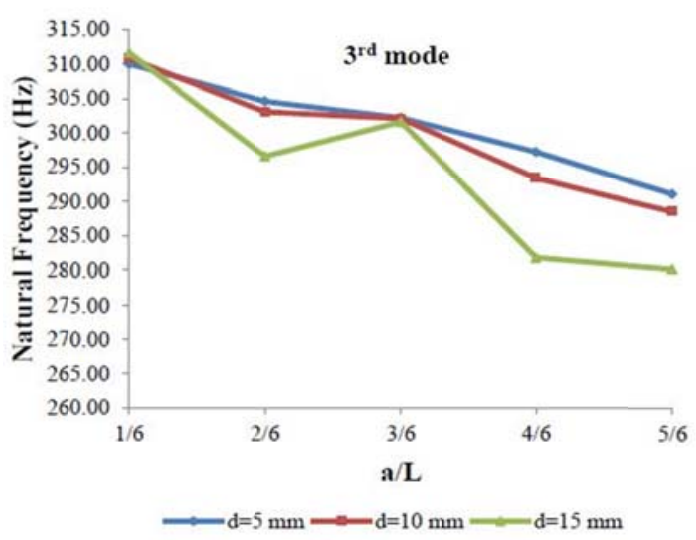

(c)

Fig. 7 Continued

Table 4 The first three out of plane natural frequencies for $L / h=100$, Temperature: $20^{\circ} \mathrm{C}$

\begin{tabular}{|c|c|c|c|c|c|c|c|c|c|c|}
\hline \multirow{2}{*}{\multicolumn{2}{|c|}{$\begin{array}{c}\text { Fiber orientation } \\
\text { Mode number }\end{array}$}} & \multicolumn{3}{|c|}{$[0 / 45 /-45 / 90]_{\mathrm{s}}$} & \multicolumn{3}{|c|}{$[45 / 0 /-45 / 90]_{\mathrm{s}}$} & \multicolumn{3}{|c|}{$[90 / 45 /-45 / 0]_{\mathrm{s}}$} \\
\hline & & 1 & 2 & 3 & 1 & 2 & 3 & 1 & 2 & 3 \\
\hline \multicolumn{2}{|c|}{$\begin{array}{c}f^{*}(\mathrm{~Hz}) \\
\text { (without hole) }\end{array}$} & 21.371 & 133.80 & 374.20 & 17.91 & 112.16 & 314.02 & 15.327 & 96.00 & 268.640 \\
\hline \multicolumn{2}{|c|}{$\begin{array}{c}\mathbf{f}(\mathrm{Hz}) \\
\text { (with hole) }\end{array}$} & & & & & & & & & \\
\hline$d(m m)$ & $a / L$ & & & & & & & & & \\
\hline \multirow{5}{*}{5} & $1 / 6$ & 19.46 & 128.92 & 364.51 & 17.103 & 109.96 & 309.96 & 16.639 & 101.25 & 278.99 \\
\hline & $2 / 6$ & 18.905 & 127.33 & 351.98 & 16.761 & 109.42 & 304.62 & 17.766 & 102.22 & 286.22 \\
\hline & $3 / 6$ & 18.712 & 121.87 & 349.59 & 16.644 & 107.08 & 302.23 & 18.375 & 105.70 & 296.19 \\
\hline & $4 / 6$ & 18.679 & 117.59 & 336.51 & 16.623 & 104.64 & 297.25 & 18.625 & 112.40 & 301.41 \\
\hline & $5 / 6$ & 18.710 & 116.66 & 326.05 & 16.648 & 103.88 & 291.11 & 18.708 & 116.27 & 320.67 \\
\hline \multirow{5}{*}{10} & $1 / 6$ & 18.977 & 128.91 & 365.32 & 16.664 & 109.88 & 310.80 & 16.005 & 100.67 & 279.83 \\
\hline & $2 / 6$ & 18.688 & 127.12 & 350.62 & 16.559 & 109.32 & 303.07 & 17.367 & 102.20 & 282.17 \\
\hline & $3 / 6$ & 18.666 & 120.56 & 349.29 & 16.599 & 105.90 & 302.13 & 18.206 & 103.62 & 295.82 \\
\hline & $4 / 6$ & 18.769 & 116.42 & 332.42 & 16.701 & 103.53 & 293.43 & 18.689 & 109.90 & 295.89 \\
\hline & $5 / 6$ & 18.953 & 116.52 & 323.32 & 16.847 & 103.74 & 288.53 & 18.928 & 115.85 & 314.79 \\
\hline \multirow{5}{*}{15} & $1 / 6$ & 17.595 & 128.67 & 365.67 & 15.405 & 109.47 & 311.60 & 14.528 & 99.32 & 281.02 \\
\hline & $2 / 6$ & 18.011 & 125.52 & 344.69 & 15.906 & 108.15 & 296.61 & 16.340 & 101.84 & 273.21 \\
\hline & $3 / 6$ & 18.449 & 119.44 & 348.24 & 16.387 & 101.44 & 301.65 & 17.808 & 98.41 & 294.80 \\
\hline & $4 / 6$ & 18.883 & 112.44 & 319.67 & 16.798 & 99.75 & 281.83 & 18.739 & 103.53 & 284.50 \\
\hline & $5 / 6$ & 19.319 & 115.85 & 314.53 & 17.109 & 103.11 & 280.13 & 19.309 & 114.46 & 299.47 \\
\hline
\end{tabular}

The location where the minimum and the maximum natural frequencies is observed does not change for the cantilever beams with $[45 / 0 /-45 / 90]_{\mathrm{s}}$ fiber orientation compared with cantilever beams with [0/45/-45/90]s fiber orientation as shown in Fig. 7. However, there is a little deviation from linear behavior for the first mode natural frequency when the hole location approaches to the right free end of the beam for the biggest diameter compared with the cantilever beams with $[0 / 45 /-45 / 90]_{\mathrm{s}}$ fiber orientation. Furthermore, the second mode frequency values decreases more 


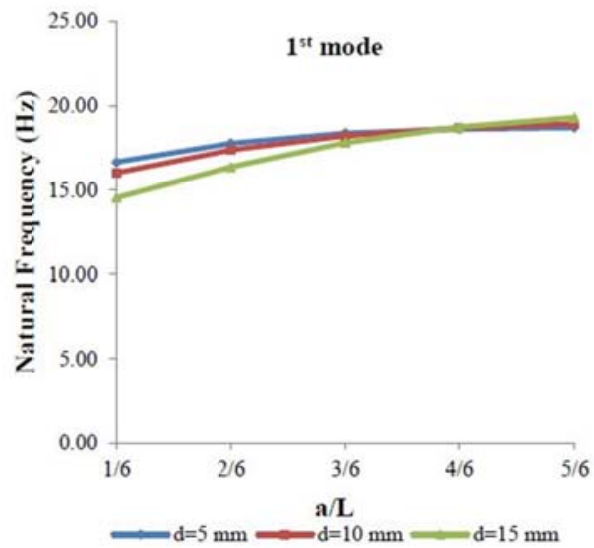

(a)

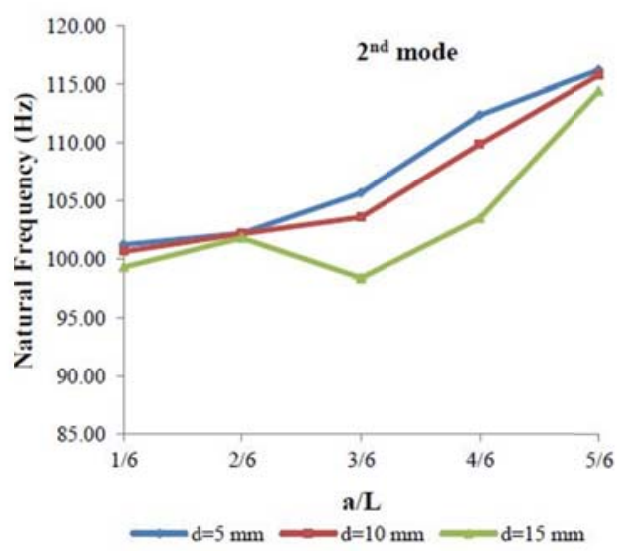

(b)

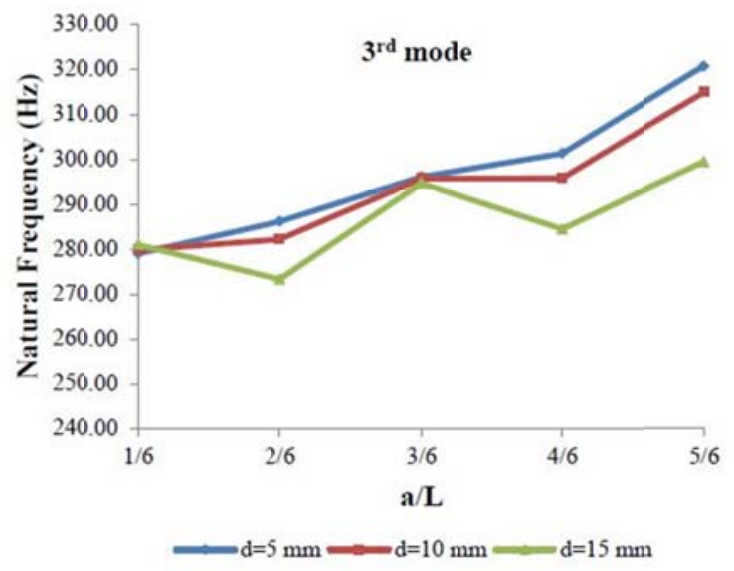

(c)

Fig. 8 The effect of $a / L$ ratios and hole diameter on the natural frequencies $(L / h=100$, Stacking sequence: $[90 / 45 /-45 / 0]_{\mathrm{s}}$, Temperature: $20^{\circ} \mathrm{C}$ )

sharply when the hole approaches to the right free end of the beam for the biggest diameter. The third mode frequency values decreases more slightly when the hole approaches to the right free end of the beam for the biggest diameter. The cantilever beams with $[90 / 45 /-45 / 0]_{\text {s }}$ fiber orientation shows different behaviour compared to the previous laminate sequences. The effect of $a / L$ ratios and hole diameter on the natural frequencies for $L / h=100$ and stacking sequence [90/45/45/0 $]_{\mathrm{s}}$ is demonstrated in Fig. 8. For all hole diameter studied, the first mode natural frequencies increase when the hole location approaches from the clamped edge to the right free end of the beam and the minimum and maximum first mode natural frequency values are observed for the biggest hole diameter as shown in Fig. 8(a). The second mode natural frequencies increase rapidly when the hole approaches from in the middle of the beam to right free end of the beam as shown in Fig. 8(b). The maximum second and the third mode natural frequency is observed when the hole location is the nearest to the free end of the beam for the smallest hole diameter as shown in Fig. 8 (b)-(c). The minimum third mode natural frequency value is observed when the hole location is the closer to the clamped edge of the beam $(a / L=2 / 6)$ for the biggest hole diameter as shown in Fig. 8(c). 


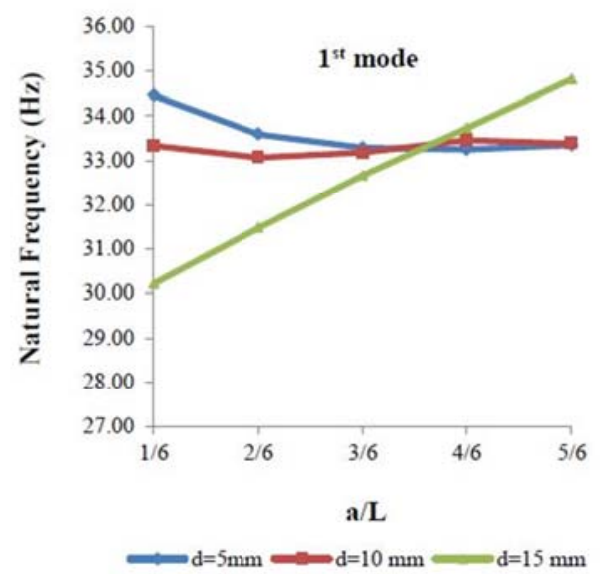

(a)

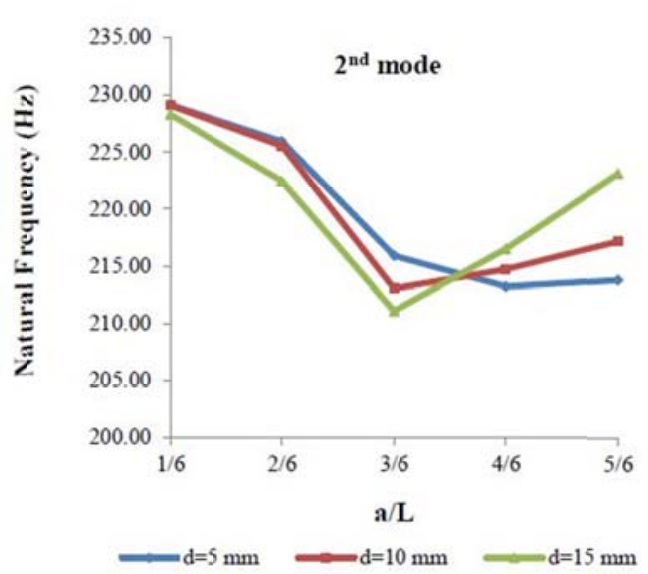

(b)

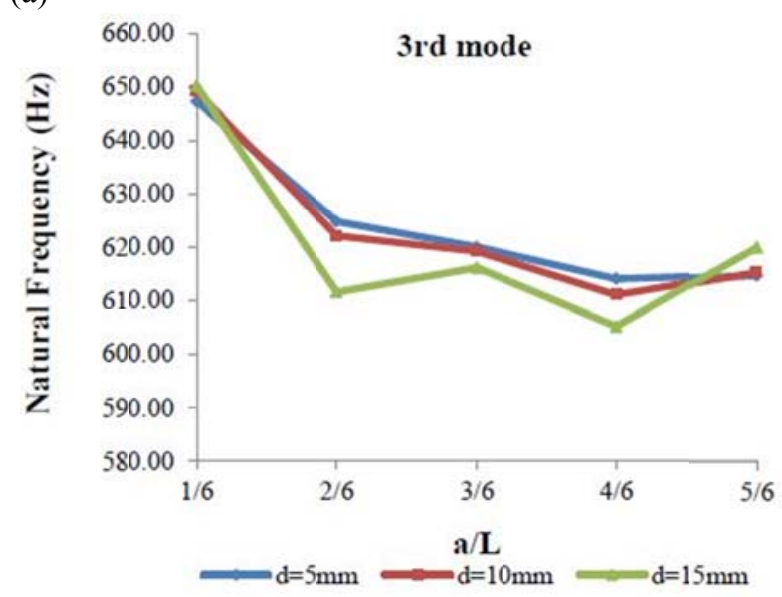

(c)

Fig. 9 The effect of $a / L$ ratios and hole diameter on the natural frequencies $(L / h=75$, Stacking sequence: $[0 / 45 /-45 / 90]_{s}$, Temperature: $20^{\circ} \mathrm{C}$ )

The exact natural frequency values are given in Table 4. It is seen that the cantilever beams with $[0 / 45 /-45 / 90]_{\mathrm{s}}$ fiber orientation have the maximum natural frequencies in all cases. It is also observed in Table 4 that the existence of the hole decreases natural frequency values for the cantilever beams with $[0 / 45 /-45 / 90]_{\mathrm{s}}$ and $[45 / 0 /-45 / 90]_{\mathrm{s}}$ fiber orientation compared with no hole. But the cantilever beams with $[90 / 45 /-45 / 0]_{s}$ fiber orientation are affected differently by the existence of the hole which increases the natural frequencies at every hole location, except when the hole location is the nearest to the clamped edge of the beam for the biggest hole diameter.

The cantilever beams with [90/45/-45/0]s fiber orientation seems to be the most influenced beams by the existence of the hole. When the beam aspect ratio is $L / h=75$, the beam behave differently if the second and the third mode natural frequencies are taken into consideration as shown in Fig. 9.

As seen in Fig. 9(a), when the biggest hole approaches to the right free end of the beam, first mode values increase linearly. The maximum and minimum first mode natural frequencies are 
observed for the biggest diameter. The same behavior is noted for the third mode natural frequency values. As shown in Fig. 9(c), the third mode natural frequency values show similar behavior when the hole diameter is $5 \mathrm{~mm}$ and $10 \mathrm{~mm}$. It can be easily seen in Fig. 9(b), the second mode values begin to decrease when the hole location approaches from the clamped left edge until in the middle of the beam for all hole diameter studied. The maximum second mode natural frequency is observed when the hole is the nearest to the clamped left edge of the beam for the smallest hole diameter.

The location where the minimum and the maximum natural frequencies is observed doesn't change for the cantilever beams with [45/0/-45/90 $]_{\mathrm{s}}$ fiber orientation compared with [0/45/-45/90 $]_{\mathrm{s}}$ laminates and the hole location effect on the natural frequencies is identical compared with having high aspect ratio $(L / h=100)$ and the same fiber orientation beams as shown in Fig. 10.

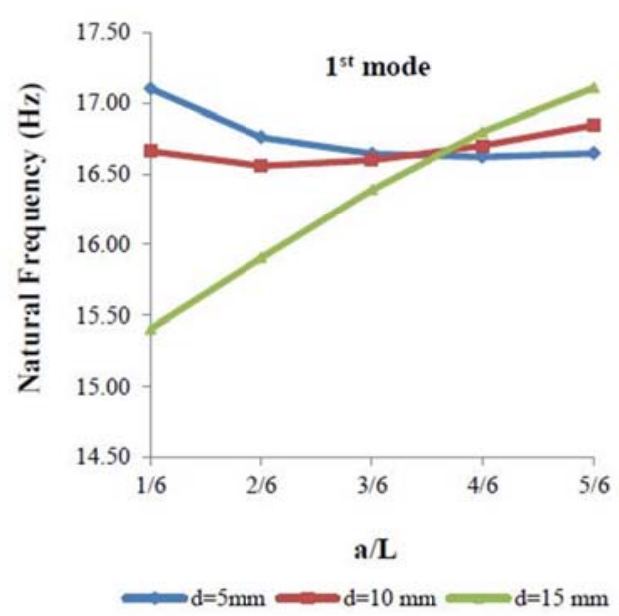

(a)

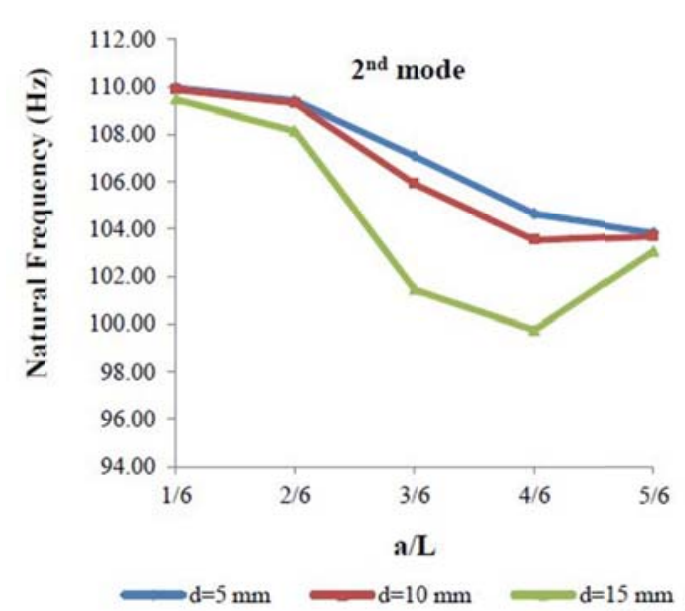

(b)

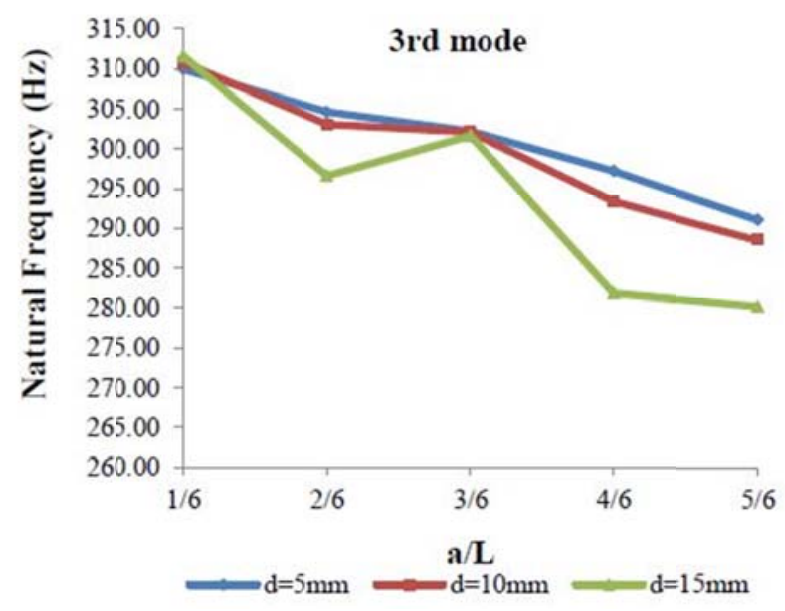

(c)

Fig. 10 The effect of $a / L$ ratios and hole diameter on the natural frequencies $(L / h=75$, Stacking sequence: $[45 / 0 /-45 / 90]_{\mathrm{s}}$, Temperature: $20^{\circ} \mathrm{C}$ ) 


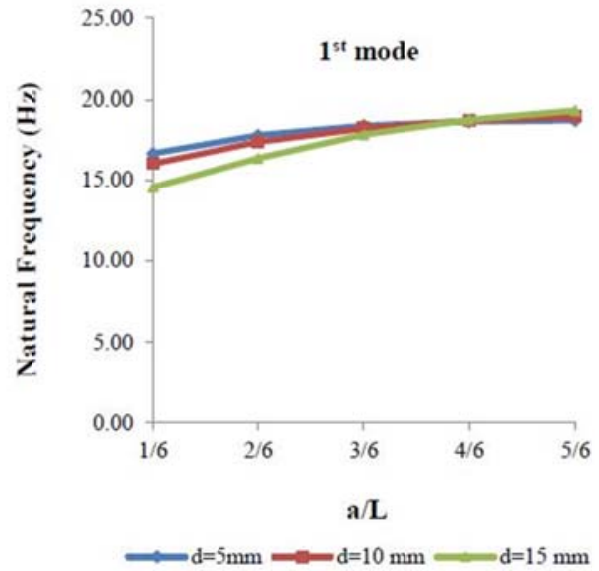

(a)

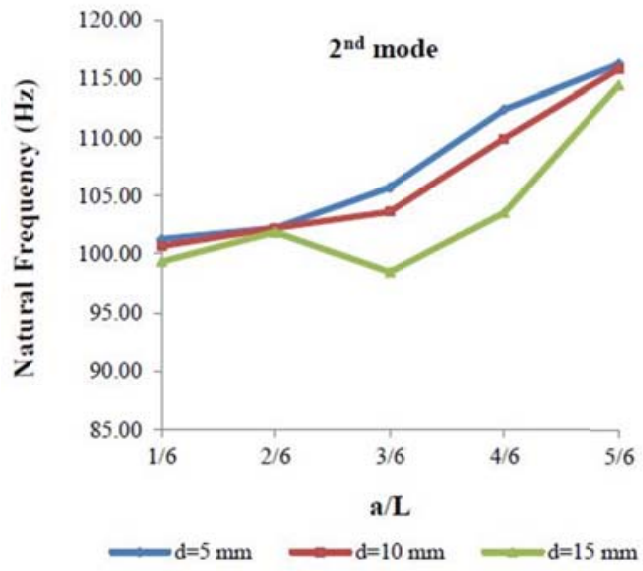

(b)

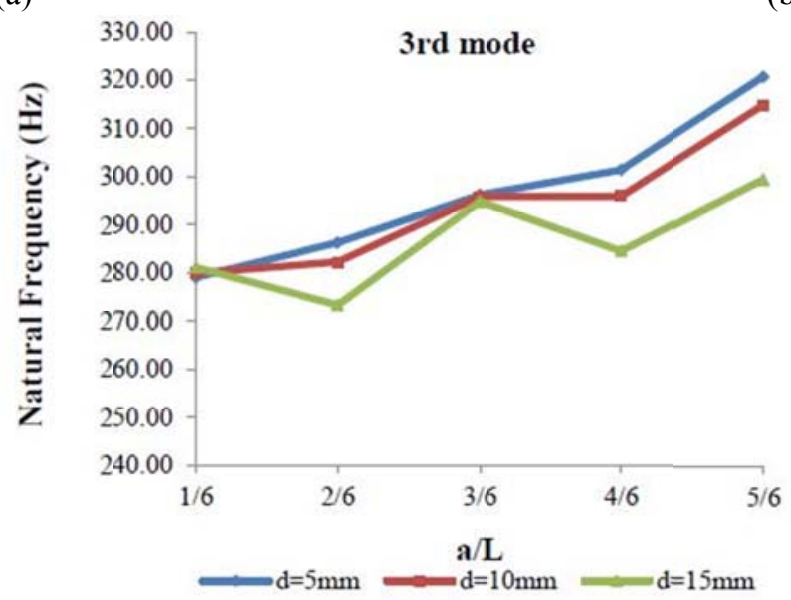

(c)

Fig. 11 The effect of $a / L$ ratios and hole diameter on the natural frequencies $(L / h=75$, Stacking sequence: $[90 / 45 /-45 / 0]_{\mathrm{s}}$, Temperature: $20^{\circ} \mathrm{C}$ )

Similarly, the cantilever beams with $[90 / 45 /-45 / 0]_{\mathrm{s}}$ fiber orientation show the same behavior compared with having high aspect ratio $(L / h=100)$ and the same fiber orientation beams as shown in Fig. 11. When the beam aspect ratio is decreased $(L / h=50)$, the hole location effect does not change compared with the previous case. Furthermore, the hole location, where the minimum and the maximum natural frequencies is observed, does not also change compared with the previous case. However, there is an exception as follows: the maximum third mode natural frequency is observed for two hole diameters $(10 \mathrm{~mm}$ and $15 \mathrm{~mm})$ when the hole location is nearest to the left clamped edge of the beam. Additionally, it can be concluded that when the beam length is shorter, the hole location effect become more important especially for the biggest hole diameter compared with the longer beams. The exact natural frequency values are given in Tables 5 and 6 . Temperature does not change the hole location effect on first three natural frequencies as shown in Fig. 12. The same behavior is observed for the second and third mode natural frequencies. The effect of stacking sequence on the first mode natural frequency for different hole location is shown 
Table 5 The first three out of plane natural frequencies for $L / h=75$, Temperature: $20^{\circ} \mathrm{C}$

\begin{tabular}{|c|c|c|c|c|c|c|c|c|c|c|}
\hline \multirow{2}{*}{\multicolumn{2}{|c|}{$\begin{array}{c}\text { Fiber orientation } \\
\text { Modenumher }\end{array}$}} & \multicolumn{3}{|c|}{$[0 / 45 /-45 / 90]_{\mathrm{s}}$} & \multicolumn{3}{|c|}{$[45 / 0 /-45 / 90]_{\mathrm{s}}$} & \multicolumn{3}{|c|}{$[90 / 45 /-45 / 0]_{\mathrm{s}}$} \\
\hline & & 1 & 2 & 3 & 1 & 2 & 3 & 1 & 2 & 3 \\
\hline \multicolumn{2}{|c|}{$f^{*}(\mathrm{~Hz})$} & 38.035 & 237.937 & 664.821 & 31.930 & 199.842 & 559.378 & 27.272 & 170.748 & 477.587 \\
\hline \multicolumn{11}{|c|}{$f(H z)$ (with hole) } \\
\hline \multirow[t]{5}{*}{$d(\mathrm{~mm})$} & $a / L$ & & & & & & & & & \\
\hline & $1 / 6$ & 34.45 & 229.16 & 647.30 & 30.456 & 196.02 & 551.69 & 29.474 & 179.76 & 496.33 \\
\hline & $2 / 6$ & 33.582 & 225.93 & 624.83 & 29.904 & 194.90 & 543.13 & 31.516 & 182.01 & 507.47 \\
\hline & $3 / 6$ & 33.281 & 215.89 & 620.04 & 29.691 & 190.67 & 537.92 & 32.669 & 187.81 & 525.27 \\
\hline & $4 / 6$ & 33.241 & 213.20 & 614.08 & 29.657 & 185.19 & 517.33 & 33.186 & 202.72 & 562.55 \\
\hline \multirow[t]{4}{*}{5} & $5 / 6$ & 33.342 & 213.77 & 614.92 & 29.735 & 185.15 & 518.60 & 33.337 & 206.56 & 567,24 \\
\hline & $1 / 6$ & 33.332 & 229.09 & 649.20 & 29.426 & 195.76 & 553.73 & 28.025 & 178.43 & 498.10 \\
\hline & $2 / 6$ & 33.063 & 225.53 & 622.12 & 29.416 & 194.71 & 539.74 & 30.596 & 182.0 & 499.19 \\
\hline & $3 / 6$ & 33.172 & 213.035 & 619.211 & 29.582 & 188.03 & 537.57 & 32.341 & 183.17 & 524.29 \\
\hline \multirow[t]{4}{*}{10} & $4 / 6$ & 33.452 & 214.71 & 611.08 & 29.843 & 182.67 & 510.16 & 33.340 & 196.75 & 545.94 \\
\hline & $5 / 6$ & 33,378 & 217.16 & 615.47 & 30.211 & 184.82 & 512.50 & 33.865 & 205.55 & 553.81 \\
\hline & $1 / 6$ & 30.207 & 228.30 & 650.19 & 26.596 & 194.63 & 555.50 & 24.804 & 175.47 & 499.98 \\
\hline & $2 / 6$ & 31.472 & 222.42 & 611.59 & 27.904 & 192.54 & 527.85 & 28.33 & 181.48 & 483.67 \\
\hline \multirow[t]{3}{*}{15} & $3 / 6$ & 32.651 & 211.05 & 616.15 & 29.071 & 178.61 & 535.92 & 31.334 & 172.70 & 521.40 \\
\hline & $4 / 6$ & 33.72 & 216.490 & 605.21 & 30.070 & 174.36 & 489.58 & 33.455 & 182.62 & 516.90 \\
\hline & $5 / 6$ & 34.816 & 223.03 & 620.15 & 31.051 & 183.26 & 493.30 & 34.792 & 202.16 & 520.55 \\
\hline
\end{tabular}

Table 6 The first three out of plane natural frequencies for $L / h=50$, Temperature: $20^{\circ} \mathrm{C}$

\begin{tabular}{|c|c|c|c|c|c|c|c|c|c|c|}
\hline \multirow{2}{*}{\multicolumn{2}{|c|}{$\begin{array}{c}\text { Fiber orientation } \\
\text { Modenumber }\end{array}$}} & \multicolumn{3}{|c|}{$[0 / 45 /-45 / 90]_{\mathrm{s}}$} & \multicolumn{3}{|c|}{$[45 / 0 /-45 / 90]_{\mathrm{s}}$} & \multicolumn{3}{|c|}{$[90 / 45 /-45 / 0]_{\mathrm{s}}$} \\
\hline & & 1 & 2 & 3 & 1 & 2 & 3 & 1 & 2 & 3 \\
\hline \multicolumn{2}{|c|}{$f^{*}(\mathrm{~Hz})$} & 85.75 & 535.198 & 1491.2 & 72.227 & 451.23 & 1261.7 & 61.465 & 384.36 & 1073.5 \\
\hline \multicolumn{2}{|c|}{$f\left(H_{z}\right)$} & & & & & & & & & \\
\hline \multirow[t]{5}{*}{$d(\mathrm{~mm})$} & $a / L$ & & & & & & & & & \\
\hline & $1 / 6$ & 76.939 & 514.502 & 1442.2 & 68.703 & 442.785 & 1242.2 & 65.857 & 402.84 & 1118.2 \\
\hline & $2 / 6$ & 75.369 & 505.315 & 1400.0 & 67.658 & 439.04 & 1226.2 & 70.635 & 410.86 & 1137.9 \\
\hline & $3 / 6$ & 74.941 & 482.16 & 1383.2 & 67.246 & 429.73 & 1212.3 & 73.473 & 421.95 & 1181.3 \\
\hline & $4 / 6$ & 75.048 & 476.80 & 1325.3 & 67.259 & 421.03 & 1187.1 & 74.776 & 445.42 & 1204.2 \\
\hline \multirow[t]{4}{*}{5} & $5 / 6$ & 75.361 & 478.75 & 1294.2 & 67.496 & 418.33 & 1170.3 & 75.343 & 463.44 & 1263.0 \\
\hline & $1 / 6$ & 73.289 & 513.71 & 1449.0 & 65.258 & 441.40 & 1249.0 & 61.203 & 398.52 & 1121.9 \\
\hline & $2 / 6$ & 73.638 & 504.74 & 1394.8 & 65.991 & 438.97 & 1217.8 & 67.628 & 410.96 & 1116.7 \\
\hline & $3 / 6$ & 74.559 & 475.30 & 1379.3 & 66.857 & 421.78 & 1210.5 & 72.363 & 408.04 & 1176.7 \\
\hline \multirow[t]{4}{*}{10} & $4 / 6$ & 75.765 & 481.47 & 1301.1 & 67.891 & 412.58 & 1162.6 & 75.284 & 427.66 & 1169.0 \\
\hline & $5 / 6$ & 77.201 & 490.15 & 1273.0 & 69.149 & 417.18 & 1149.9 & 77.166 & 459.93 & 1220.8 \\
\hline & $1 / 6$ & 64.132 & 509.09 & 1449.0 & 56.615 & 429.87 & 1251.8 & 51.887 & 389.41 & 1120.9 \\
\hline & $2 / 6$ & 68.553 & 498.05 & 1379.5 & 61.078 & 434.62 & 1197.1 & 60.686 & 410.51 & 1090.7 \\
\hline \multirow[t]{3}{*}{15} & $3 / 6$ & 72.777 & 465.36 & 1363.2 & 65.084 & 396.78 & 1200.9 & 69.032 & 381.16 & 1162.3 \\
\hline & $4 / 6$ & 76.662 & 485.14 & 1242.1 & 68.644 & 387.04 & 1105.9 & 75.619 & 389.11 & 1118.1 \\
\hline & $5 / 6$ & 80.564 & 510.08 & 1212.5 & 72.166 & 411.63 & 1090.8 & 80.475 & 448.07 & 1127.9 \\
\hline
\end{tabular}



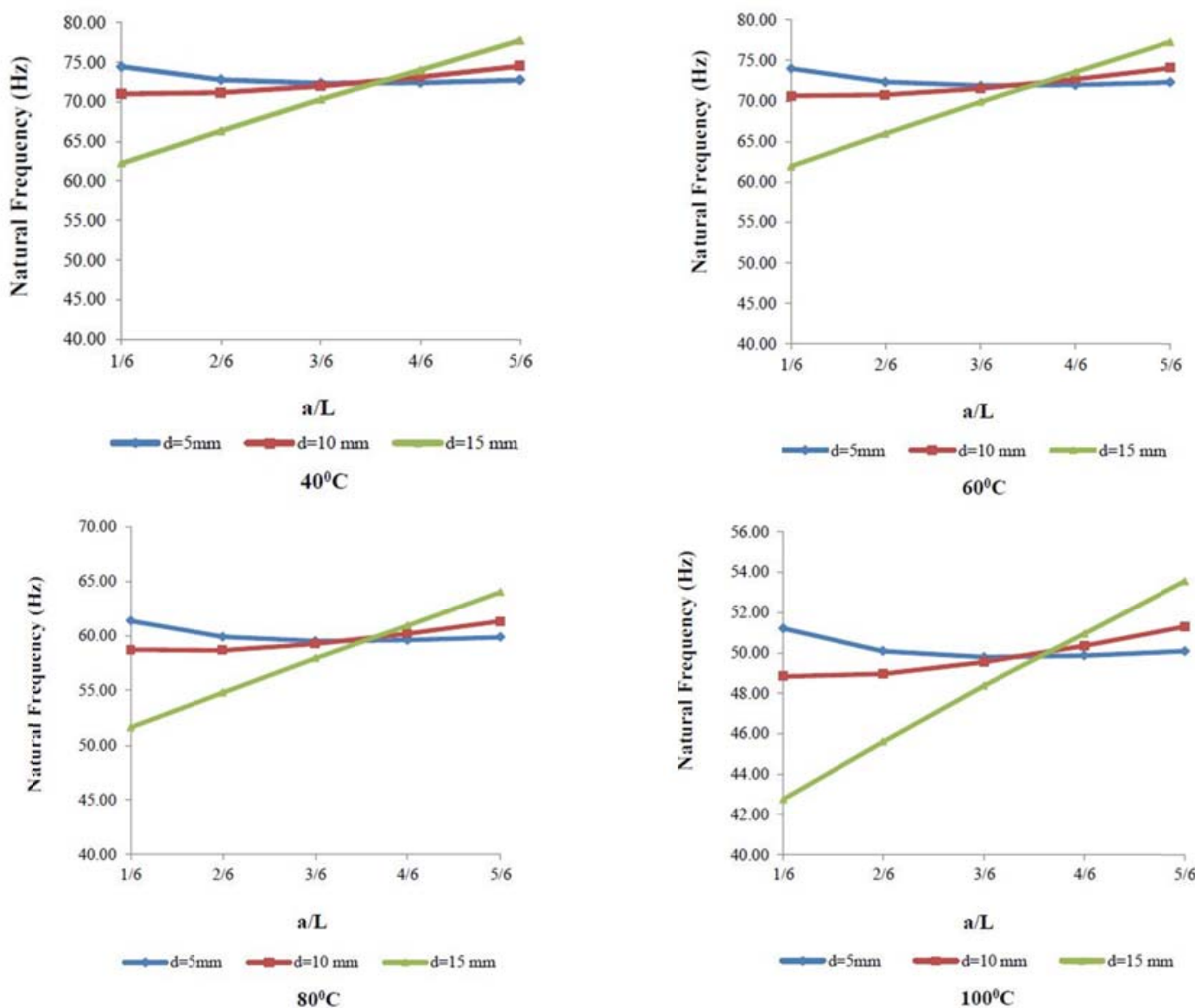

Fig. 12 The effect of different temperatures on the first mode natural frequencies $(L / h=50$, Stacking sequence: $[0 / 45 /-45 / 90]_{\mathrm{s}}$ )

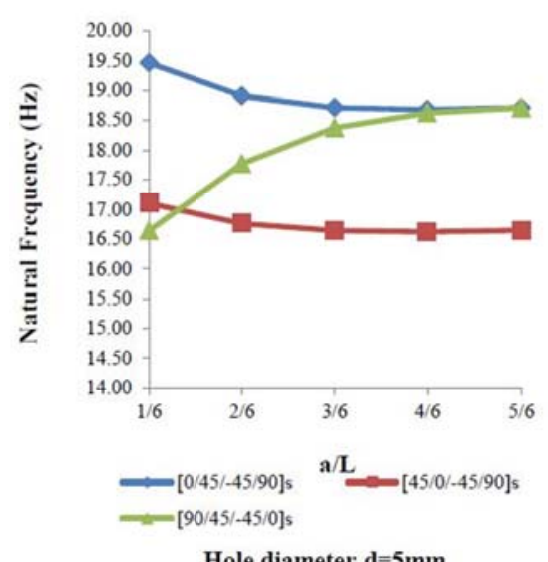

Hole diameter $\mathbf{d}=\mathbf{5} \mathrm{mm}$

(a)

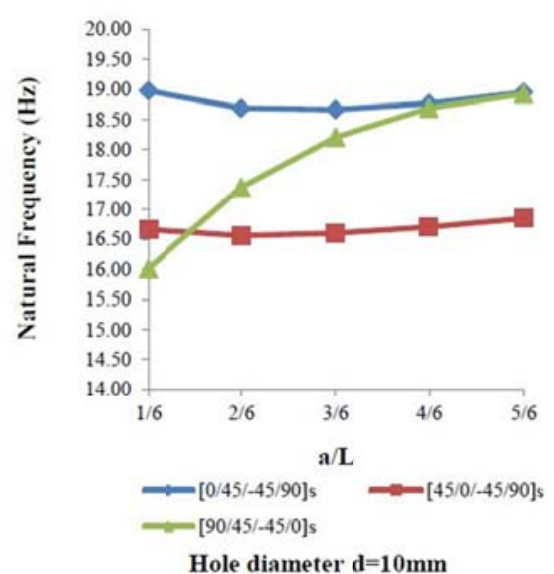

(b)

Fig. 13 The effect of stacking sequence on the first mode natural frequencies for different hole location $\left(\mathrm{L} / \mathrm{h}=100\right.$, Temperature: $\left.20^{\circ} \mathrm{C}\right)$ 


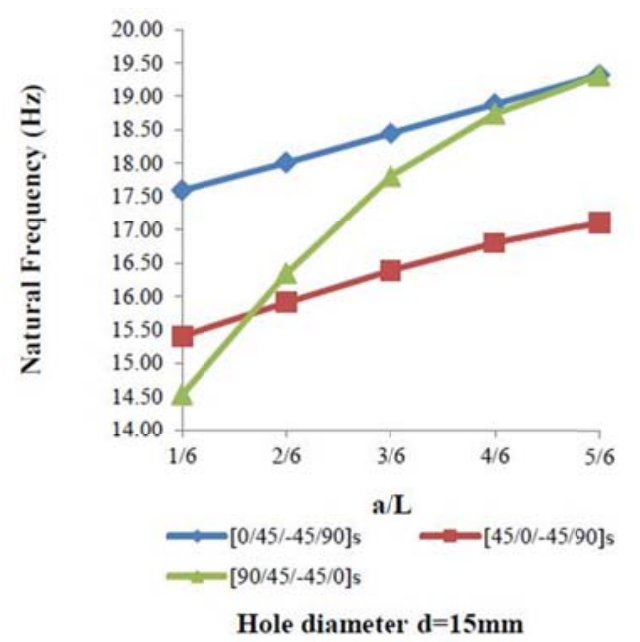

Fig. 13 Continued

in Fig. 13. It is seen that if the hole diameter is $5 \mathrm{~mm}$ and $10 \mathrm{~mm}$, cantilever beams with $[0 / 45 /-45$ $90]_{\mathrm{s}}$ fiber orientation show similar behavior when the hole location becomes closer to the right free end of the beam. However, cantilever beams with $[90 / 45 /-45 / 0]_{\mathrm{s}}$ fiber orientation show different behavior compared with the others. When the hole approaches to the right free end of the beam $\left(a / L=4 / 6\right.$, and 5/6), cantilever beams with $[90 / 45 /-45 / 0]_{\mathrm{s}}$ fiber orientation show similar behavior compared with the beams having $[0 / 45 /-45 / 90]_{\mathrm{s}}$ orientation. When the hole diameter is biggest, for all cases, natural frequency values begin to increase from the left clamped edge to right free end of the beam continuously.

\section{Conclusions}

The conclusions drawn from the study can be summarized as:

The natural frequencies show important decreases from stacking sequence $[0 / 45 /-45 / 90]_{\mathrm{s}}$, to $[45 / 0 /-45 / 90]_{\mathrm{s}}$ and from $[45 / 0 /-45 / 90]_{\mathrm{s}}$ to $[90 / 45 /-45 / 0]_{\mathrm{s}}$. The cantilever beams with $[0 / 45 /-45 / 90]_{\mathrm{s}}$ fiber orientation have the maximum natural frequencies in all cases. When the beam length is decreased from $L / h=100$ to $L / h=75$, and from $L / h=75$ to $L / h=50$ the natural frequency values increase ceaselessly. The cantilever beams with $[90 / 45 /-45 / 0]_{\mathrm{s}}$ fiber orientation seems to be the most influenced beams by the existence of the holes. The existence of the holes increases the natural frequencies at some locations for $[90 / 45 /-45 / 0]_{\mathrm{s}}$ orientations compared to the cantilever beams with the same fiber orientation without hole. The hole location and hole diameter have important influence especially on the second and third mode natural frequencies. The results show that when the temperature increases, the frequency values decrease for all cases and natural frequencies show important decreases from $60^{\circ} \mathrm{C}$ to $80^{\circ} \mathrm{C}$, and from $80^{\circ} \mathrm{C}$ to $100^{\circ} \mathrm{C}$. The points mentioned above show us that the designer can change the laminate stacking sequence, hole location and hole diameter in order to acquire the desired natural frequencies. 


\section{References}

Abramovich, H. (1992), "Shear deformation and rotary inertia effects of vibrating composite beams", Compos. Struct., 20(3), 165-173.

Abramovich, H., Eisenberger, M. and Shulepov, O. (1995), "Dynamic stiffness matrix for symmetrically laminated beams using a first order shear deformation theory”, Compos. Struct., 31(4), 265-271.

Aksu, G. and Ali, R. (1976), "Determination of dynamic characteristics of rectangular plates with cut-outs using a finite difference formulation", J. Sound Vib., 44(1), 147-158.

Aktas, M. and Karakuzu, R. (2009), "Determination of mechanical properties of glass-epoxy composites in high temperatures", Polym. Compos, 30(10), 1347-1441.

Alam, M.N., Upadhyay, N.K. and Anas M. (2012), "Efficient finite element model for dynamic analysis of laminated composite beam", Struct. Eng. Mech, 42(4), 471-488.

Bezazi, A., El Mahi, A., Berthelot, J.M. and Bezzazi, B. (2001), “Analyse de l'endommagement des stratifiés en flexion 3-points", Proceedings of the XVème Congrès Français de Mécanique, France, September.

Bezazi, A., El Mahi, A., Berthelot, J.M. and Bezzazi, B. (2003a), "Flexural fatigue behavior of cross-ply laminates: An experimental approach”, Strength Mater., 35(2), 149-161.

Bezazi, A., El Mahi, A., Berthelot, J.M. and Kondratas, A. (2003b), "Investigation of cross-ply laminates behavior in three-point bending tests. Part II: Cyclic fatigue tests", Mat. Sci., 9(1), 128-133.

Chandrashekhara, K. and Bangera, K.M. (1992), "Free vibration of composite beams using a refined shear flexible element”, Comput. Struct., 43(4), 719-727.

Davidson, B.D., Krüger, R. and Konig, M. (1995), "Three-dimensional analysis of center-delaminated unidirectional and multidirectional single-leg bending specimens", Compos. Sci. Technol., 54(4), 385-394.

El Mahi, A., Berthelot, J.M. and Brillaud, J. (1995), "Stiffness reduction and energy release rate of cross-ply laminates during fatigue tests”, Compos. Struct., 30(2), 123-130.

Hassan, G.A., Fahmy, M.A. and Mohammed, I.G. (2009), "Effects of fiber orientation and laminate stacking sequence on out-of plane and in-plane bending natural frequencies of laminated composite beams", Proceedings of $9^{\text {th }}$ PEDAC Conference, Egypt, February.

Hodges, H.D., Atilgan, A.R., Fulton, M.V. and Rehfield, L.W. (1991), "Free vibration analysis of composite beams", J. Am. Helicopt. Soc., 36(3), 36-47.

Khdeir, A.A. (1994), "Free vibration of cross-ply laminated beams with arbitrary boundary conditions", Int. J. Eng. Sci., 32(12), 1971-1980.

Kim, C.S., Young, P.G. and Dickinson, S.M. (1990), "On the flexural vibration of rectangular plates approached by using simple polynomials in the Rayleigh-Ritz method", J. Sound Vib., 143(3), 379-394.

Kim, N.I. and Choi D.H. (2013), "Super convergent laminated composite beam element for lateral stability analysis", Steel Compos. Struct., 15(2), 175-202.

Kisa, M. (2004), "Free vibration analysis of a cantilever composite beam with multiple cracks", Compos. Sci. Technol., 64(9), 1391-1402.

Krishnaswamy, S., Chandrahekhara, K. and Wu, W.Z.B. (1992), "Analytical solution to vibration of generally layered composite beams", J. Sound Vib., 159(1), 85-99.

Kwon, Y.W. and Bang, H. (2000), The finite element method using Matlab, 2nd Edition, Dekker Mechanical Engineering Series, CRC Press, Boca Raton.

Lee, C.Y., Liu, D. and Lu, X. (1992), "Static and vibration analysis of laminated composite beams with an interlaminar shear stress continuity theory", Int. J. Numer. Meth. Struct. Eng., 33(2), 409-424.

Lee, H.S. (1984), "Transverse vibration of rectangular plates having an inner cutout in water", J. Soc. Nav. Arch. Korea, 21(1), 21-34.

Maiti, K.D. and Sinha, P.K. (1994), "Bending and free vibration analysis of shear deformable laminated composite beams by finite element method", Compos. Struct., 29(4), 421-431.

Paramasivam, P. (1973), "Free vibration of square plates with square opening”, J. Sound Vib., 30(2), 173178. 
Rajamani, A. and Prabhakaran, R. (1977), "Dynamic response of composite plates with cut-outs. Part II: Clamped-clamped plates", J. Sound Vib., 54(4), 565-576.

Ram, K.S. and Sinha, P.K. (1992), "Hygrothermal effects on the free vibration of laminated composite plates", J. Sound Vib., 158(1), 133-148.

Sakiyama, T., Huang, M., Matsuda, H. and Morita, C. (2003), "Free vibration of orthotropic square plates with a square hole", J. Sound Vib., 259(1), 63-80.

Sharma, A.K. and Mittal, N.D. (2010), "Review on stress and vibration analysis of composite plates", $J$. Appl. Sci., 10(23), 3156-3166.

Shi, G. and Lam, K.Y. (1999), "Finite-element vibration analysis of composite beams based on a higherorder beam theory", J. Sound Vib., 219(4), 707-721.

Sun, C.T. and Jen, K.C. (1987), "On the effect of matrix cracks on laminate strength", J. Reinf. Plast. Comp., 6(3), 208-223.

Teboub, Y. and Hajela, P. (1995), "Free vibration of generally layered composite beams using symbolic computations", Compos. Struct., 33(3), 123-134.

Teh, K.K. and Huang, C.C. (1979), "The vibrations of generally orthotropic beams, a finite element approach", J. Sound Vib., 62(2), 195-206. 